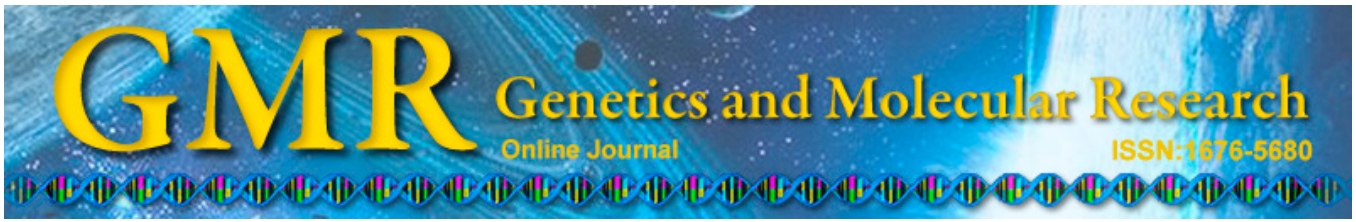

\title{
Interaction of six candidate genes in essential hypertension
}

\author{
D.C. Hu, X.L. Zhao, J.C. Shao, W. Wang, J. Qian, A.H. Chen, \\ H.Q. Zhang, H. Guo, J. Jiang and H.Y. Li
}

Department of Clinical Laboratory, The First People's Hospital of Kunming, The Key Clinical Molecular Biology Laboratory of Kunming, Kunming, China

Corresponding author: D.C. Hu

E-mail: dachunhu@163.com

Genet. Mol. Res. 13 (4): 8385-8395 (2014)

Received January 12, 2014

Accepted June 18, 2014

Published October 20, 2014

DOI http://dx.doi.org/10.4238/2014.October.20.14

\begin{abstract}
We explored the interaction of 6 candidate genetic mutations in essential hypertension (EH). The mutations AGT M235T, ACE I/D, eNOS Glu298Asp, ET-2 A985G, ANP T2238C, and NPRC A-55C were detected using a genechip microarray in 100 patients with $\mathrm{EH}$ and 97 controls from the Han population living in the Yunnan Province of China. Risks of EH were evaluated with respect to a combination of these genotypes. Interactions were analyzed using multifactor dimensionality reduction (MDR). P values were corrected using Bonferroni's adjustment. Results showed that CC genotype frequencies for NPRC A-55C (0.540) in EH were significantly higher than those in controls $\left(0.237, \mathrm{P}_{\mathrm{c}}<0.01\right.$; odds ratio $(\mathrm{OR})=3.777 ; 95 \%$ confidence interval $(\mathrm{CI})=2.050-6.960)$. The OR for NPRC A-55C CC combined with ET-2 A985G GG increased to 4.673 and to 5.529 when the MT genotype of AGT M235T, the EE genotype of eNOS Glu298Asp, the GG genotype of ET-2 A985G, and the CC genotype of NPRC A-55C were combined. MDR showed that ET-2/NPRC is the best model $(\mathrm{OR}=4.002 ; 95 \% \mathrm{CI}=2.1597-7.4159)$. The $\mathrm{CC}$ genotype for NPRC A-55C and the G allele for ET-2 A985G were associated with susceptibility to EH. Although the contributions of the candidate genes
\end{abstract}


differ, they may have cooperative effects on conferring risk for EH. Moreover, potential gene-gene interactions were found between ET-2 A985G and NPRC A-55C in EH.

Key words: Essential hypertension; Gene polymorphism; Genechip microarray; Gene-gene interaction

\section{INTRODUCTION}

Essential hypertension (EH) is one of the most common diseases of human being, and also is an important cause for the myocardial infarction, cerebral apoplexy, and some serious nephropathy, etc. (Whitworth, 2003). As a complex disorder that threatens against people's health, EH has no identifiable cause up to now. Data from the study of animal models, human twins, and family disease histories indicated that $30-60 \%$ variation of the blood pressure derives from genetic changes (Binder, 2007).

In recent years, there is some important development in the knowledge of $\mathrm{EH}$ genetic etiology, but not as clear as about the monogenic inheritant hypertension. A large quantity of research by one-dimensional genome-wide scanning has been performed, and almost every chromosome has linked loci related to the blood pressure variability. But meta-analysis on these papers could not provide the evidence for even suggestive multiple genes of EH (Puddu et al., 2007). It is popularly believed that $\mathrm{EH}$ is the result of interactions of gene-gene or genecircumstance. In the exploration of EH genetic etiology, the researches on multigene interaction showed much more significance.

The RAS system, vascular endothelial system, and NP family and its receptors have a vital role in blood pressure regulation and hypertension pathological mechanism; thus, the coding gene mutations have been extensively studied. Several scholars worldwide have studied the correlation between some gene mutations and the changes in blood pressure and hypertension. The gene mutations included AGT M235T, ACE I/D, eNOS Glu298Asp, ET-2 A985G, ANP T2238C, and NPRC A-55C. However, their results were diverse (Jeunemaitre et al., 1992, Staessen et al., 1997; Kato et al., 1999; Sarzani et al., 1999; Agerholm-Larsen et al., 2000; Benjafield and Morris, 2000; Williams et al., 2000; Jáchymová et al., 2001; Rossi et al., 2003; Mondry et al., 2005; Pereira et al., 2007; Periaswamy et al., 2008; Srivastava et al., 2008). We assume that these related genes may have mutual or synergistic effects on regulation of blood pressure after gene mutations.

In polygenic diseases, the genes may come into high-order interactions, which could not be efficiently analyzed by current statistical methods. Traditional parametric statistics such as logistic regression models or generalized linear models requiring cumbersome process and large sample sizes may make the type II errors arise, and hardly can explain the result. Furthermore, the genotype and phenotype of polygenic diseases are not linear relationship, the logistic regression models will increase type I and II errors (Moore, 2003) or have curse of dimensionality (Moore and Ritchie, 2004). In 2001, Ritchie first proposed multifactor dimensionality reduction (MDR) that was applied to the analysis of gene-gene interactions. MDR is a nonparametric analytical method, with no need for genetic models and interaction models. The method does not need a large sample, and fits for the analysis of 2-6-locus interaction, including case-control or sib pair with different diseases.

Present research, Han people in Yunnan Province were chosen as the study object. Six candidate gene loci in 3 different system RAS, vascular endothelium and natriuretic peptides were studied on their gene-gene interactions by the MDR statistical method. 


\section{MATERIAL AND METHODS}

\section{Subjects}

The patient group included 100 patients who visited our hospital between January 2002 and March 2007 and who were eligible for participation in the study. This study was conducted in accordance with the Declaration of Helsinki and with approval from the Ethics Committee of the First People's Hospital of Kunming. Written informed consent was obtained from all participants. The control group comprised 97 healthy individuals who underwent physical examination in our hospital during the same period.

The inclusion criterion for all subjects was as follows: confirmation of Yunnan Han nationality based on paternal and maternal line being of Han nationality for 3 generations who have resided in Yunnan Province. Further inclusion criteria for the patient group were based on the 2004 China Guideline on Prevention and Management of Hypertension, as follows: at least 3 consecutive systolic blood pressure (SBP) measurements $\geq 140 \mathrm{mmHg}$ or diastolic blood pressure (DBP) measurements $\geq 90 \mathrm{mmHg}$, or receiving antihypertensive pharmacotherapy treatment for at least 1 year; suffering from hypertension and 30-70 years old; no clinical or laboratory information indicating that they had secondary hypertension. The particular inclusion criteria for the control group were as follows: no blood relationship with other members of the patient group, and no family history of hypertension; SBP $<140 \mathrm{mmHg}$ or DBP $<90 \mathrm{mmHg} ; \geq 40$ years of age.

The following data were collected from the patient group and the control group: gender, age, body mass index, hypertension history, SBP, DBP, serum total cholesterol (TC), serum triglyceride (TG), high-density lipoprotein cholesterol (HDL-C), low-density lipoprotein cholesterol (LDL-C), and fasting plasma glucose (FPG).

\section{Detection of genetic polymorphisms}

Genetic polymorphisms in 6 candidate gene loci, including AGT M235T (MM, MT, TT), ACE I/D (II, ID, DD), eNOS Glu298Asp (EE, ED, DD), ET-2 A985G (AA, AG, GG), ANP T2238C (TT, TC, CC), and NPRC A-55C (AA, AC, CC), were detected using gene chips from Shanghai Baio Biotech Co. Ltd. (Shanghai, China).

\section{Statistical analysis}

The distribution frequency of the 6 candidate gene loci was calculated by direct counting. Representative samples were judged by comparing the genetic polymorphism frequency to Hardy-Weinberg equilibrium expectations by using the $\chi^{2}$ test. The distributions of genetic polymorphisms were compared using the $\chi^{2}$ test, and the criterion of significance was $\alpha=0.05$. SPSS13.0 was employed for analysis of enumeration data and measurement data (SPSS, Inc., Chicago, IL, USA). The P value was corrected using Bonferroni's adjustment.

For correlation analysis of the patient and control groups, the relative risk factor was evaluated using the odds ratio (OR). Susceptibility to hypertension was considered when OR $>1$ and a protective effect was considered when $\mathrm{OR}<1$.

\section{Polygenic transactional analysis}

Polygenic stacking effects were analyzed by using combination modes of multiple genetic loci. Polygenetic interactions were analyzed by the MDR method using the MDR 
1.10 software. The best combination pattern of the AGT M235T, ACE I/D, eNOS Glu298Asp (E298D), ET-2 A985G, ANP T2238C, and NPRC A-55C genetic polymorphisms was searched on the principle that both cross-validation consistency and test balance accuracy were maximized in order to evaluate the interactions of the 6 genes in relation to hypertension.

\section{RESULTS}

\section{Patient and control group characteristics}

Characteristics of the 100 patients and 97 healthy controls are listed in Table 1. Differences in hypertension history, SBP, and DBP between the patient and control groups were highly significant $(\mathrm{P}<0.01)$, and the differences in HDL-C, LDL-C, and FPG were significant $(\mathrm{P}<0.05)$.

Table 1. Characteristics of patients with essential hypertension and healthy controls.

\begin{tabular}{lcc}
\hline Group & Patients $(\mathrm{N}=100)$ & Controls $(\mathrm{N}=97)$ \\
\hline Gender (male/female) & $48 / 52$ & $42 / 55$ \\
Age (years) & $57.71 \pm 9.97$ & $55.05 \pm 10.64$ \\
BMI $\left(\mathrm{kg} / \mathrm{m}^{2}\right)$ & $23.79 .5 \pm 2.99$ & $24.24 \pm 4.50$ \\
Hypertension history (years) & $7.72 \pm 4.73$ & $0.00^{\Delta \Lambda}$ \\
SBP $(\mathrm{mmHg})$ & $171.47 \pm 13.01$ & $115.66 \pm 10.99^{\Delta \Delta}$ \\
DBP $(\mathrm{mmHg})$ & $100.74 \pm 8.34$ & $73.49 \pm 8.15^{\Delta \Delta}$ \\
TC $(\mathrm{mM})$ & $4.91 \pm 0.80$ & $4.83 \pm 0.78$ \\
TG $(\mathrm{mM})$ & $1.78 \pm 0.93$ & $1.88 \pm 1.35$ \\
HDL-C (mM) & $1.25 \pm 0.29$ & $1.51 \pm 0.59^{\Delta}$ \\
LDL-C (mM) & $2.91 \pm 0.73$ & $2.46 \pm 0.83^{\Delta}$ \\
FPG $(\mathrm{mM})$ & $5.40 \pm 1.78$ & $4.75 \pm 0.57^{\Delta}$ \\
\hline
\end{tabular}

Data are reported as means $\pm \mathrm{SD} . \mathrm{BMI}=$ body mass index; $\mathrm{SBP}=$ systolic blood pressure; $\mathrm{DBP}=$ diastolic blood pressure; $\mathrm{TC}=$ total cholesterol; $\mathrm{TG}=$ total triglycerides; $\mathrm{HDL}-\mathrm{C}=$ high-density lipoprotein cholesterol; $\mathrm{LDL}-\mathrm{C}=$ low-density lipoprotein cholesterol; FPG $=$ fasting plasma glucose. ${ }^{\Delta} \mathrm{P}<0.01,{ }^{\Delta} \mathrm{P}<0.05$.

\section{Frequency distribution of the genetic polymorphisms}

The AGT M235T (MM, MT, TT), ACE I/D (II, ID, DD), eNOS Glu298Asp (EE, ED, DD), ET-2 A985G (AA, AG, GG), ANP T2238C (TT, TC, CC), and NPRC A-55C (AA, AC, CC) genetic polymorphisms were analyzed for deviations from Hardy-Weinberg equilibrium test; the results indicated that the samples were representative of the population $(P>0.05)$.

Figure 1 shows one of the gene chips reacting with the sample from the control subject No. 10. Figure 2 shows one of the gene chips reacting with a sample from patient No. 86 . The genotypes of the 6 loci in the two individuals are listed in Table 2. The allele frequency distributions of the 97 Yunnan Han healthy people and the 100 Yunnan Han EH patients for these 6 loci are shown in Table 3. The genotype frequency distributions of the 6 loci are listed in Table 4 .

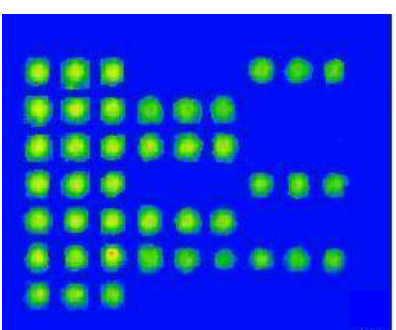

Figure 1. Gene chip reacting with a sample from the control subject No. 10. 


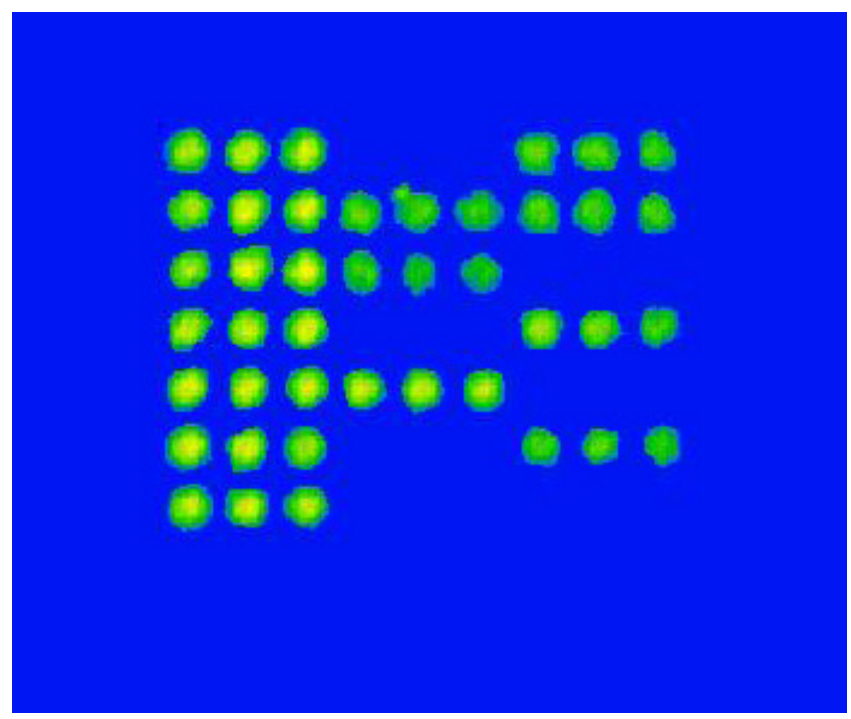

Figure 2. Gene chip reacting with a sample from the patient No. 86 .

Table 2. Detection in controls and patients by gene chip.

\begin{tabular}{|c|c|c|c|c|}
\hline \multirow[t]{2}{*}{ Gene } & \multicolumn{2}{|c|}{ Control } & \multicolumn{2}{|c|}{ Patient } \\
\hline & Locus & Genotype & Locus & Genotype \\
\hline AGT & 235 & TT & 235 & TT \\
\hline $\mathrm{ACE}$ & Insertion/Deletion & II & Insertion/Deletion & DI \\
\hline eNOS & 298 & $\mathrm{EE}$ & 298 & $\mathrm{EE}$ \\
\hline ET-2 & 985 & GG & 985 & GG \\
\hline ANP & 2238 & TT & 2238 & TT \\
\hline NPRC & -55 & $\mathrm{AC}$ & -55 & $\mathrm{CC}$ \\
\hline
\end{tabular}

Table 3. Allele frequencies (AF) of 6 loci in control and patient groups.

\begin{tabular}{|c|c|c|c|c|c|c|c|c|}
\hline \multirow[t]{2}{*}{ Allele } & \multicolumn{2}{|c|}{ Control $(\mathrm{N}=194)$} & \multicolumn{2}{|c|}{ Patient $(N=200)$} & \multirow[t]{2}{*}{$\chi^{2}$} & \multirow[t]{2}{*}{$\mathrm{P}$} & \multirow[t]{2}{*}{ Odds ratio } & \multirow[t]{2}{*}{$95 \% \mathrm{CI}$} \\
\hline & $\mathrm{N}$ & $\mathrm{AF}$ & $\mathrm{N}$ & $\mathrm{AF}$ & & & & \\
\hline AGT M235T & & & & & 1.289 & 0.2560 & & \\
\hline $\mathrm{M}$ & 47 & 0.242 & 39 & 0.195 & & & & \\
\hline $\mathrm{T}$ & 147 & 0.758 & 161 & 0.805 & & & & \\
\hline ACE I/D & & & & & 0.105 & 0.7460 & & \\
\hline I & 130 & 0.680 & 139 & 0.695 & & & & \\
\hline D & 64 & 0.320 & 61 & 0.305 & & & & \\
\hline eNOS E298D & & & & & 4.768 & $0.0290 *$ & & \\
\hline E & 178 & 0.918 & 195 & 0.975 & & & & \\
\hline $\mathrm{D}$ & 16 & 0.082 & 5 & 0.025 & & & & \\
\hline ET-2 A985G & & & & & 5.507 & $0.0190 *$ & & \\
\hline A & 29 & 0.149 & 15 & 0.075 & & & & \\
\hline $\mathrm{G}$ & 165 & 0.851 & 185 & 0.925 & & & 2.648 & $1.073-6.536$ \\
\hline ANP T2238C & & & & & 0.178 & 0.6730 & & \\
\hline $\mathrm{T}$ & 190 & 0.979 & 197 & 0.985 & & & & \\
\hline $\mathrm{C}$ & 4 & 0.021 & 3 & 0.015 & & & & \\
\hline NPRC A-55C & & & & & 10.663 & 0.0010 & & \\
\hline A & 74 & 0.381 & 46 & 0.230 & & & & \\
\hline $\mathrm{C}$ & 120 & 0.619 & 154 & 0.770 & & & 2.064 & $1.331-3.201$ \\
\hline
\end{tabular}


Table 4. Genotype frequencies (GF) of 6 loci in control and patient groups.

\begin{tabular}{|c|c|c|c|c|c|c|c|c|}
\hline \multirow[b]{2}{*}{ Genotype } & \multicolumn{2}{|c|}{ Control $(\mathrm{N}=97)$} & \multicolumn{2}{|c|}{ Patient $(N=100)$} & \multirow[t]{2}{*}{$\chi^{2}$} & \multirow[t]{2}{*}{ P } & \multirow[t]{2}{*}{ Odds ratio } & \multirow[t]{2}{*}{$95 \% \mathrm{CI}$} \\
\hline & $\mathrm{N}$ & GF & $\mathrm{N}$ & GF & & & & \\
\hline ATG M235T & & & & & 1.429 & 0.4900 & & \\
\hline MM & 5 & 0.052 & 4 & 0.040 & & & & \\
\hline MT & 37 & 0.381 & 31 & 0.310 & & & & \\
\hline TT & 55 & 0.567 & 65 & 0.650 & & & & \\
\hline ACE I/D & & & & & 1.053 & 0.5910 & & \\
\hline II & 33 & 0.340 & 41 & 0.410 & & & & \\
\hline DI & 58 & 0.598 & 54 & 0.540 & & & & \\
\hline DD & 6 & 0.062 & 5 & 0.050 & & & & \\
\hline eNOS E298D & & & & & 8.175 & 0.017 & & \\
\hline $\mathrm{EE}$ & 82 & 0.845 & 96 & 0.960 & & & & \\
\hline $\mathrm{DE}$ & 14 & 0.144 & 3 & 0.030 & & & & \\
\hline DD & 1 & 0.011 & 1 & 0.010 & 0.000 & 0.983 & & \\
\hline ET-2 A985G & & & & & 5.907 & 0.0520 & & \\
\hline AA & 2 & 0.020 & 0 & 0.000 & & & & \\
\hline AG & 25 & 0.258 & 15 & 0.150 & & & & \\
\hline GG & 70 & 0.722 & 85 & 0.850 & & & & \\
\hline ANP T2238C & & & & & 0.181 & 0.6700 & & \\
\hline TT & 93 & 0.959 & 97 & 0.970 & & & & \\
\hline CT & 4 & 0.041 & 3 & 0.030 & & & & \\
\hline $\mathrm{CC}$ & 0 & 0.000 & 0 & 0.000 & & & & \\
\hline NPRC A-55C & & & & & 18.973 & 0.0000 & & \\
\hline AA & 0 & 0.000 & 0 & 0.000 & & & & \\
\hline $\mathrm{AC}$ & 74 & 0.763 & 46 & 0.460 & & & & \\
\hline $\mathrm{CC}$ & 23 & 0.237 & 54 & 0.540 & & & 3.777 & $2.050-6.960$ \\
\hline
\end{tabular}

\section{Association of genetic polymorphisms with EH}

In the patient group, the frequencies of 5 genetic polymorphisms, including AGT M235 (MM, MT, TT), ACE I/D (II, ID, DD), eNOS Glu298ASP, ET-2 A985G (AA, AG, GG), and ANP T2238C (TT, TC, CC), showed no significant difference compared to those of the control group. However, in the patient group, the CC genotype frequency $(0.540)$ and the $\mathrm{C}$ allele genotype frequency $(0.770)$ of NPRC A-55C were significantly different from those of the control group (genotype: $0.237 ; \chi^{2}=18.973, \mathrm{P}_{c}<0.01$, and allele: $0.619 ; \chi^{2}=10.663, \mathrm{P}_{c}$ $=0.006)$. The OR for the CC genotype was $3.77(95 \% \mathrm{CI}=2.050-6.960), \chi^{2}=17.632$ and $\mathrm{P}_{\mathrm{c}}=$ 0.01 in the $\mathrm{M}-\mathrm{H}$ test, and the $\mathrm{OR}$ for the $\mathrm{C}$ allele was $2.064(95 \% \mathrm{CI}=1.331-3.021)$.

\section{Superposition effect analysis for the 6 loci}

The superposition effect and interactions were analyzed among the 6 loci: AGT M235T, ACE I/D, eNOS Glu298ASP, ET-2 A985G, ANP T2238C, and NPRC A-55C. A total of 123 different combinations of the 6 genetic polymorphisms were analyzed, and the combination genetic frequencies of 2 to 5 loci were significantly different from the control group, as shown in Table 5. This was because the CT genotype frequencies of the ANP T2238C locus were extremely low and the $\mathrm{CC}$ genotype frequencies were 0 in both the patient and control groups. There was little effect after the 6 loci were stacked; the CT and CC genotypes of ANP T2238C are not listed in Table 5. A combination of ET-2 A985G and NPRC A-55C CC increased the OR to 4.673 from 3.777 obtained for the single-locus NPRC A-55C CC. The combination of 4 loci, including AGT M235T MT, eNOS Glu298Asp EE, ET-2 A985G GG, and NPRC A-55C CC, further increased the OR to 5.529. These results indicate that mutations in these 4 candidate loci had varying impacts on EH pathogenesis, and that the 4 loci had a superposition effect. 
Table 5. Genotype frequencies of 2-5 loci combined in control and patient groups.

\begin{tabular}{|c|c|c|c|c|c|c|c|c|c|c|c|}
\hline AGT & $\mathrm{ACE}$ & eNOS & ET-2 & ANP & NPRC & Control [N (\%)] & Patient [N (\%)] & $\chi^{2}$ & $\mathrm{P}$ & Odds ratio & $95 \% \mathrm{CI}$ \\
\hline \multicolumn{12}{|c|}{ Two-way } \\
\hline MT & - & - & - & - & $\mathrm{CC}$ & $7(7.2)$ & $20(20)$ & 6.803 & 0.009 & 3.214 & $1.291-8.000$ \\
\hline MT & - & - & - & - & $\mathrm{AC}$ & $27(27.8)$ & 11 (11) & 8.964 & 0.003 & 0.32 & $0.149-0.691$ \\
\hline TT & - & - & - & - & $\mathrm{CC}$ & 13 (13.4) & $31(31)$ & 8.791 & 0.003 & 2.903 & $1.411-5.574$ \\
\hline- & II & - & GG & - & - & 21 (21.6) & $36(36)$ & 4.931 & 0.026 & 2.036 & $1.081-3.832$ \\
\hline - & II & - & - & - & $\mathrm{CC}$ & $10(10.3)$ & $24(24)$ & 6.463 & 0.011 & 2.747 & $1.235-6.110$ \\
\hline - & ID & - & - & - & $\mathrm{CC}$ & $13(13.4)$ & $29(29)$ & 7.142 & 0.008 & 2.639 & $0.327-1.328$ \\
\hline - & ID & - & - & - & $\mathrm{AC}$ & $45(46.4)$ & $26(26)$ & 8.882 & 0.003 & 0.406 & $0.223-0.739$ \\
\hline - & - & $\mathrm{EE}$ & GG & - & - & $58(58.0)$ & $79(79)$ & 8.575 & 0.003 & 2.53 & $1.348-4.747$ \\
\hline - & - & ED & - & TT & - & $16(16.5)$ & $7(7.0)$ & 4.305 & 0.038 & 0.381 & $0.149-0.972$ \\
\hline - & - & $\mathrm{EE}$ & - & TT & - & $77(79.4)$ & $90(90)$ & 4.301 & 0.038 & 2.338 & $1.032-5.296$ \\
\hline - & - & ED & - & - & $\mathrm{AC}$ & $15(15.5)$ & $4(4.0)$ & 7.426 & 0.006 & 0.228 & $0.073-0.713$ \\
\hline - & - & EE & - & - & $\mathrm{CC}$ & 21 (21.6) & $51(51)$ & 18.291 & 0 & 3.767 & $2.022-7.018$ \\
\hline - & - & $\mathrm{EE}$ & - & - & $\mathrm{AC}$ & $59(60.8)$ & $42(42)$ & 7.743 & 0.005 & 0.448 & $0.253-0.792$ \\
\hline- & - & $\mathrm{EE}$ & GG & - & - & $66(68.0)$ & $81(81)$ & 4.366 & 0.037 & 2.002 & $1.038-3.863$ \\
\hline - & - & & - & TT & $\mathrm{CC}$ & $22(22.7)$ & $51(51)$ & 16.93 & 0 & 3.548 & $1.916-6.570$ \\
\hline - & - & - & - & TT & $\mathrm{AC}$ & $71(73.2)$ & $46(46)$ & 15.1 & 0 & 0.312 & $0.172-0.567$ \\
\hline - & - & - & $\mathrm{AG}$ & - & $\mathrm{AC}$ & 19 (19.6) & $9(9.0)$ & 4.527 & 0.033 & 0.406 & $0.174-0.949$ \\
\hline - & - & - & GG & - & $\mathrm{CC}$ & $16(16.5)$ & $48(48)$ & 22.283 & 0 & 4.673 & $2.405-9.081$ \\
\hline - & - & - & GG & - & $\mathrm{AC}$ & $54(55.7)$ & $37(37)$ & 6.905 & 0.009 & 0.468 & $0.264-0.827$ \\
\hline \multicolumn{12}{|c|}{ Three-way } \\
\hline MM & - & $\mathrm{EE}$ & GG & - & - & $36(36)$ & $52(52)$ & 4.415 & 0.036 & 1.836 & $1.039-3.242$ \\
\hline MT & - & - & - & TT & $\mathrm{CC}$ & 7 (7.2) & $18(18)$ & 5.168 & 0.023 & 2.822 & $1.121-7.102$ \\
\hline MT & - & - & - & TT & $\mathrm{AC}$ & $27(27.8)$ & $11(11)$ & 8.964 & 0.003 & 0.32 & $0.149-0.691$ \\
\hline TT & - & - & - & TT & $\mathrm{CC}$ & $13(13.4)$ & $31(31)$ & 8.791 & 0.003 & 2.903 & $1.411-5.974$ \\
\hline- & II & EE & GG & - & - & $19(19.6)$ & $33(33)$ & 4.559 & 0.033 & 2.022 & $1.053-3.881$ \\
\hline - & II & - & GG & TT & - & $20(20.6)$ & $35(35)$ & 5.06 & 0.024 & 2.073 & $1.093-3.935$ \\
\hline - & II & - & - & TT & $\mathrm{CC}$ & $10(10.3)$ & $23(23)$ & 5.687 & 0.017 & 2.599 & $1.164-5.820$ \\
\hline - & ID & - & - & TT & $\mathrm{CC}$ & $12(12.4)$ & $27(27)$ & 6.636 & 0.01 & 2.62 & $1.239-5.538$ \\
\hline - & ID & - & - & TT & $\mathrm{AC}$ & $43(44.3)$ & $26(26)$ & 7.269 & 0.007 & 0.441 & $0.242-0.804$ \\
\hline - & - & $\mathrm{EE}$ & GG & TT & - & $55(56.7)$ & $76(76)$ & 8.232 & 0.004 & 2.418 & $1.314-4.450$ \\
\hline - & - & ED & - & $\mathrm{TT}$ & $\mathrm{AC}$ & $14(14.4)$ & $4(4)$ & 6.456 & 0.011 & 0.247 & $0.078-0.780$ \\
\hline - & - & $\mathrm{EE}$ & - & TT & $\mathrm{CC}$ & $20(20.6)$ & $48(48)$ & 16.332 & 0 & 3.554 & $1.894-6.667$ \\
\hline- & - & $\mathrm{EE}$ & - & TT & $\mathrm{AC}$ & $57(58.8)$ & $42(42)$ & 5.534 & 0.019 & 0.508 & $0.288-0.896$ \\
\hline MT & ID & - & - & - & $\mathrm{AC}$ & $20(20.6)$ & $6(6)$ & 9.185 & 0.002 & 0.246 & $0.094-0.642$ \\
\hline TT & ID & - & - & - & $\mathrm{CC}$ & $7(7.2)$ & $19(19)$ & 5.968 & 0.015 & 3.016 & $1.205-7.546$ \\
\hline- & II & $\mathrm{EE}$ & - & - & $\mathrm{CC}$ & $10(10.3)$ & $22(22)$ & 4.946 & 0.026 & 2.454 & $1.096-5.503$ \\
\hline - & ID & $\mathrm{EE}$ & - & - & $\mathrm{CC}$ & $11(11.3)$ & $28(28)$ & 8.607 & 0.003 & 3.04 & $1.416-6.503$ \\
\hline- & ID & $\mathrm{EE}$ & - & - & $\mathrm{AC}$ & $40(41.2)$ & $22(22)$ & 8.449 & 0.004 & 0.402 & $0.216-0.749$ \\
\hline - & - & $\mathrm{EE}$ & GG & - & $\mathrm{CC}$ & $15(15.5)$ & $46(46)$ & 21.478 & 0 & 4.657 & $2.368-9.159$ \\
\hline \multicolumn{12}{|c|}{ Four-way } \\
\hline- & ID & $\mathrm{EE}$ & GG & - & $\mathrm{CC}$ & $8(8.2)$ & $25(25)$ & 9.909 & 0.002 & 3.708 & $1.580-8.705$ \\
\hline - & ID & $\mathrm{EE}$ & GG & - & $\mathrm{AC}$ & $31(32)$ & $18(18)$ & 5.134 & 0.023 & 0.467 & $0.240-0.909$ \\
\hline MT & & $\mathrm{EE}$ & GG & - & $\mathrm{CC}$ & $3(3.1)$ & $15(15)$ & 8.409 & 0.004 & 5.529 & $1.547-19.765$ \\
\hline TT & & $\mathrm{EE}$ & GG & - & $\mathrm{CC}$ & $9(9.3)$ & $28(28)$ & 11.314 & 0.001 & 3.802 & $1.686-8.574$ \\
\hline MT & II & - & GG & - & $\mathrm{CC}$ & $2(2.1)$ & $9(9)$ & 4.496 & 0.034 & 4.698 & $0.988-22.332$ \\
\hline MT & DD & - & GG & - & $\mathrm{AC}$ & $15(15.5)$ & $4(4)$ & 7.426 & 0.006 & 0.228 & $0.073-0.713$ \\
\hline TT & ID & - & GG & - & $\mathrm{CC}$ & $5(5.2)$ & $17(17)$ & 6.964 & 0.008 & 3.769 & $1.332-10.666$ \\
\hline MT & ID & $\mathrm{EE}$ & - & - & $\mathrm{AC}$ & $18(18.6)$ & $6(6)$ & 7.257 & 0.007 & 0.28 & $0.106-0.740$ \\
\hline MM & ID & $\mathrm{EE}$ & - & - & $\mathrm{CC}$ & $6(6.2)$ & $18(18)$ & 6.424 & 0.011 & 3.329 & $1.261-8.791$ \\
\hline \multicolumn{12}{|c|}{ Five-way } \\
\hline MT & ID & $\mathrm{EE}$ & GG & - & $\mathrm{CC}$ & $1(1)$ & $8(8)$ & 5.485 & 0.019 & 8.348 & $1.024-68.063$ \\
\hline MT & ID & $\mathrm{EE}$ & GG & - & $\mathrm{AC}$ & $13(13.4)$ & $4(4)$ & 5.52 & 0.019 & 0.269 & $0.085-0.857$ \\
\hline TT & ID & $\mathrm{EE}$ & GG & - & $\mathrm{CC}$ & $5(5.2)$ & $17(17)$ & 6.964 & 0.008 & 3.769 & $1.332-10.666$ \\
\hline
\end{tabular}

\section{Analysis of gene-gene interactions with the MDR method}

The MDR software was used to analyze the gene-gene interactions between the 6 loci, including AGT M235T MT, eNOS Glu298Asp EE, ET-2 A985G GG, and NPRC A-55C CC, in the patient group. Table 6 shows that combinations of 2 of the loci, ET-2/NPRC, 3 of the loci, ACE/eNOS/NPRC, and 4 of the loci, ACE/eNOS/ET-2/NPRC, were statistically significant $(\mathrm{P}<0.001)$. However, the 2-locus ET-2/NPRC model showed the largest cross-validation consistency coefficient at 9 of 10 . Hence, the optimum model contained ET-2 A985G and 
NPRC A-55C, indicating that these 2 loci may interact. The OR of the ET-2/NPRC model was $4.002(95 \% \mathrm{CI}=2.1597-7.4159)$.

Table 6. Model of gene-gene interaction of the 6 candidate loci and their properties.
\begin{tabular}{lccc}
\hline Model & ET-2/NPRC & ACE/eNOS/NPRC & ACE/eNOS/ET-2/NPRC \\
\hline Training accuracy & 0.657 & 0.6718 & 0.6908 \\
Test accuracy & 0.6297 & 0.6416 & 0.5967 \\
$\chi^{2}$ & 20.3831 & 24.4024 & 27.1310 \\
Significance test (P) & $10(0.0010)$ & $10(0.0010)$ & $10(0.0010)$ \\
Cross-validation consistency & $9 / 10$ & $5 / 10$ & $5 / 10$ \\
Sensitivity & 0.5400 & 0.5600 & 0.6700 \\
Specificity & 0.7732 & 0.7835 & 0.7010 \\
Odds ratio & 4.002 & 4.6061 & 4.7607 \\
$95 \%$ CI & $2.1597-7.4159$ & $2.4679-8.5967$ & $2.6068-8.6942$ \\
\hline
\end{tabular}

\section{DISCUSSION}

Recently, numerous studies have been conducted to examine the relationship between EH and the AGT M235T, ACE I/D, and eNOS Glu298Asp genetic polymorphisms to understand the genetic contribution to the hypertension pathological mechanism. AGT was the first and the most thoroughly studied candidate gene for its potential involvement in EH disease. More than 500 studies have been published regarding correlations of the AGT M235T locus with EH and other cardiovascular diseases (Rosskopf et al., 2007). In North America, Europe, Australia, Japan, and China, both positive and negative results have been reported regarding the relationship between AGT 235T and EH; however, no positive results have been reported in the Caribbean, USA, and in the African-American population. Numerous meta-analyses have indicated that the OR of AGT 235T for EH in Caucasians was 1.22-1.60; the absolute effect was quite limited, and its contribution to blood pressure was less than $1 \mathrm{mmHg}$. In the present study, no correlation between AGT 235T and EH in the Yunnan Han population was observed.

Although studies examining the pathological mechanism of EH have demonstrated that increased ACE activity in plasma may be explained by the presence of the ACE D allele, the results of several reports evaluating the correlation between the ACE I/D polymorphism and $\mathrm{EH}$ are not consistent. Staessen et al. (1997) conducted the first meta-analysis of this relationship, including 28 cases, which indicated that DD genotype carriers had a $10 \%$ increased risk for EH after combining the negative results. Further sub-analyses showed that the risk in females and Asians was statistically significant. Subsequently, Agerholm-Larsen et al. (2000) conducted a meta-analysis involving 15,942 Caucasians in Germany, and suggested that the contribution of the DD genotype to blood pressure change was only $0.5 \mathrm{mmHg}$. In 2005 , Mondry et al. (2005) found no correlation between the ACE I/D polymorphism and EH. In the current study, neither the single-locus ACE I/D genotype or allele frequency in the patient group was significantly different from those of the control group. However, 4-locus gene combination analysis showed that the combination of the OR was significantly increased (5.529) when 4 loci were combined: AGT-MT, eNOS-EE, ET-2-GG, and NPRC-CC. In the analysis of gene-gene interactions using the MDR method, although ACE I/D on its own was not the best model, it was nonetheless included in the optimal ACE/eNOS/NPRC 3-locus interactive model and in the ACE/eNOS/ET-2/NPRC 4-locus interactive model. These results indicate that the ACE I/D polymorphism is not a major EH gene, but may have a synergistic effect in 
multi-minor gene stacking and reciprocity.

A large number of studies examining the correlation between eNOS Glu298Asp and EH have been reported, but the results are variable (Miyamoto et al., 1998; Kato et al., 1999; Benjafield and Morris, 2000; Jáchymová et al., 2001; Rossi et al., 2003; Periaswamy et al., 2008; Srivastava et al., 2008). Pereira et al. (2007) carried out a meta-analysis including 53 separate studies to examine the correlation between eNOS genotypes and $\mathrm{EH}$ in various populations. In Asians, the 298Asp allele was predicted to be related to EH with an OR of $1.28(95 \% \mathrm{CI}=1.06-$ 1.54), and the contribution to SBP and DBP was $2 \mathrm{mmHg}$; this relationship may also depend on serum TC levels. They also found that the correlation of the eNOS gene mutation and EH was heterogeneous, and that publication bias was evident. In the present study of the Yunnan Han population, we were unable to demonstrate a correlation between eNOS and EH because the homozygote, heterozygote of 298Asp, and allele of 298Asp showed very low frequencies.

Sharma et al. (1999) found that a mutation in the A985G base group of the ET-2 gene's 3'-untranslated region (UTR) could be considered an independent predictive factor in untreated EH patients. Sarzani et al. (1999) examined the NPRC A-55C polymorphism of obesity-related hypertension patients and found that $-55 \mathrm{CC}$ homozygote carriers had relatively low ANP levels and high SBPs. Correlations between EH and ET-2 A985G, ANP T2238C, and NPRC A-55C have not been extensively reported. In our study of the Yunnan Han people, no AA genotype was detected in the ET-2 A985G locus of the patient group, and the GG genotype frequency was not significantly different from that of the control group; however, the $\mathrm{G}$ allele frequency was higher than that in the control group, with an OR of $2.648(95 \% \mathrm{CI}=1.073$ 6.536). The mutation rates of ANP T2238C in both the patient and control groups were very low; the $\mathrm{CC}$ genotype was not detected, and the frequency of the $\mathrm{C}$ allele was approximately $2 \%$. Thus, the ANP T2238 CC genotype has little influence on EH. In the selected 6 candidate genes, a mutation in NPRC A-55C showed a strong positive correlation with $\mathrm{EH}$, and the CC genotype frequency was clearly higher than that in the control group, with an OR of 3.777 $(95 \% \mathrm{CI}=2.050-6.960)$. These results indicate that the mutation in NPRC A-55C may be involved in $\mathrm{EH}$.

Few studies have been conducted to examine the relationship between $\mathrm{EH}$ and multigene interactions because of the limitation of appropriate genetic statistical methods. Based on studies of polygene interactions in AGT, ACE, and AT1R loci using a candidate gene linkage disequilibrium analysis method, Williams et al. (2000) demonstrated that gene-gene interactions are significant in hypertension etiology. The interaction between the genotypes of the 6 loci, AGT M235T, ACE I/D, eNOS Glu298Asp, ET-2 A985G, ANP T2238C, and NPRC A$55 \mathrm{C}$, of our $100 \mathrm{EH}$ patients was analyzed. In the 2- to 5-locus combination genetic analysis, a combination of ET-2 A985G and NPRC A-55C CC increased the OR to 4.673 from that obtained for the single-locus NPRC A-55C CC (3.777). In the 4-locus combination, AGT M235T MT, eNOS Glu298Asp EE, ET-2 A985G GG, and NPRC A-55C CC increased the OR to 5.529. These results indicate that the 6 candidate genes had varying influences on $\mathrm{EH}$ pathogenesis; the 5-locus combination showed a superposition effect, excluding ANP T2238C. ACE I/D, eNOS Glu298Asp EE, ET-2 A985G, and NPRC A-55C CC were found to participate in effective models in the analysis of gene-gene interactions using the MDR method. ET-2 A985G GG and NPRC A-55C were included in the optimum model and had a high OR of $4.002(95 \% \mathrm{CI}=2.1597-7.4159)$. The mutation in the ET-2 3'-UTR (A985G) base group was shown to not only be related to hypertension susceptibility, but also demonstrated a superposition effect to minor gene reciprocity. NPRC A-55C was the most important polymorphism 
identified in our locus mutation interactions. The exact mechanism of the NPRC -55C homozygote in hypertension is not yet clear; however, based on the results of Sarzani et al. (1999), and the physiological function of NPRC (eliminating ANP in serum), it can be hypothesized that the mutation in the NPRC $-55 \mathrm{C}$ base group increases NPRC expression, and subsequently decreases the ANP level, thereby increasing blood pressure. Confirming the precise pathological mechanism requires further investigation in more populations.

\section{ACKNOWLEDGMENTS}

Research supported by Key Scientific and Technological Projects of Kunming City, China (\#04S06013-03).

\section{REFERENCES}

Agerholm-Larsen B, Nordestgaard BG and Tybjaerg-Hansen A (2000). ACE gene polymorphism in cardiovascular disease: meta-analyses of small and large studies in whites. Arterioscler. Thromb. Vasc. Biol. 20: 484-492.

Benjafield AV and Morris BJ (2000). Association analyses of endothelial nitric oxide synthase gene polymorphisms in essential hypertension. Am. J. Hypertens. 13: 994-998.

Binder A (2007). A review of the genetics of essential hypertension. Curr. Opin. Cardiol. 22: 176-184.

Jáchymová M, Horký K, Bultas J, Kozich V, et al. (2001). Association of the Glu298Asp polymorphism in the endothelial nitric oxide synthase gene with essential hypertension resistant to conventional therapy. Biochem. Biophys. Res. Commun. 284: 426-430.

Jeunemaitre X, Soubrier F, Kotelevtsev YV, Lifton RP, et al. (1992). Molecular basis of human hypertension: role of angiotensinogen. Cell 71: 169-180.

Kato N, Sugiyama T, Morita H, Nabika T, et al. (1999). Lack of evidence for association between the endothelial nitric oxide synthase gene and hypertension. Hypertension 33: 933-936.

Miyamoto Y, Saito Y, Kajiyama N, Yoshimura M, et al. (1998). Endothelial nitric oxide synthase gene is positively associated with essential hypertension. Hypertension 32: 3-8.

Mondry A, Loh M, Liu P, Zhu AL (2005). Polymorphisms of the insertion/deletion ACE and M235T AGT genes and hypertension: surprising new findings and meta-analysis of data. BMC Nephrol. 6-1.

Moore JH (2003). The ubiquitous nature of epistasis in determining susceptibility to common human diseases. Hum. Hered. 56: 73-82.

Moore JH and Ritchie MD (2004). STUDENTJAMA. The challenges of whole-genome approaches to common diseases. JAMA 291: 1642-1643.

Pereira TV, Rudnicki M, Cheung BM, Baum L, et al. (2007). Three endothelial nitric oxide (NOS3) gene polymorphisms in hypertensive and normotensive individuals: meta-analysis of 53 studies reveals evidence of publication bias. $J$. Hypertens. 25: 1763-1774.

Periaswamy R, Gurusamy U, Shewade DG, Cherian A, et al. (2008). Gender specific association of endothelial nitric oxide synthase gene (Glu298Asp) polymorphism with essential hypertension in a south Indian population. Clin. Chim. Acta 395: 134-136.

Puddu P, Puddu GM, Cravero E, Ferrari E, et al. (2007). The genetic basis of essential hypertension. Acta Cardiol. 62: 281-293.

Ritchie MD, Hahn LW, Roodi N, Bailey LR, et al. (2001). Multifactor-dimensionality reduction reveals high-order interactions among estrogen-metabolism genes in sporadic breast cancer. Am. J. Hum. Genet. 69: 138-147.

Rossi GP, Taddei S, Virdis A, Cavallin M, et al. (2003). The T-786C and Glu298Asp polymorphisms of the endothelial nitric oxide gene affect the forearm blood flow responses of Caucasian hypertensive patients. J. Am. Coll. Cardiol. 41: 938-945.

Rosskopf D, Schurks M, Rimmbach C and Schafers R (2007). Genetics of arterial hypertension and hypotension. $N$. Schmied. Arch. Pharmacol. 374: 429-469.

Sarzani R, Dessi-Fulgheri P, Salvi F, Serenelli M, et al. (1999). A novel promoter variant of the natriuretic peptide clearance receptor gene is associated with lower atrial natriuretic peptide and higher blood pressure in obese hypertensives. $J$. Hypertens. 17: 1301-1305.

Sharma P, Hingorani A, Jia H, Hopper R, et al. (1999). Quantitative association between a newly identified molecular variant in the endothelin-2 gene and human essential hypertension. J. Hypertens. 17: 1281-1287. 
Srivastava K, Narang R, Sreenivas V, Das S, et al. (2008). Association of eNOS Glu298Asp gene polymorphism with essential hypertension in Asian Indians. Clin. Chim. Acta 387: 80-83.

Staessen JA, Wang JG, Ginocchio G, Petrov V, et al. (1997). The deletion/insertion polymorphism of the angiotensin converting enzyme gene and cardiovascular-renal risk. J. Hypertens. 15: 1579-1592.

Whitworth JA (2003). 2003 World Health Organization (WHO)/International Society of Hypertension (ISH) statement on management of hypertension. J. Hypertens. 21: 1983-1992.

Williams SM, Addy JH, Phillips JA, III, Dai M, et al. (2000). Combinations of variations in multiple genes are associated with hypertension. Hypertension 36: 2-6. 